\title{
Visible Light-Induced Partial Oxidation of Olefins on Cr-Containing Silica with Molecular Oxygen
}

Yasuhiro Shiraishi, ${ }^{*}$ Yugo Teshima, and Takayuki Hirai

Research Center for Solar Energy Chemistry, and Division of Chemical Engineering, Graduate School of

Engineering Science, Osaka University, Toyonaka 560-8531, Japan

E-mail: shiraish@cheng.es.osaka-u.ac.jp

\section{Supporting Information}

Table S1. Detailed product distributions in the photooxidation of styrene and $\alpha$-methylstyrene ${ }^{a}$

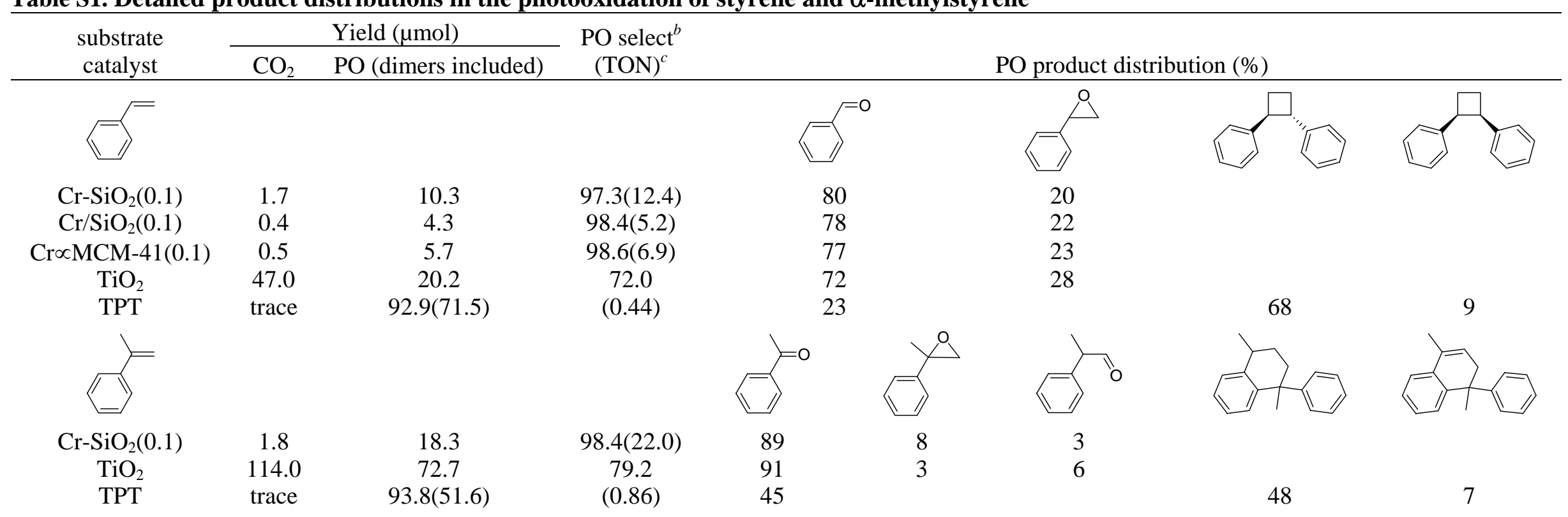

${ }^{a}$ Reaction conditions: acetonitrile, $10 \mathrm{~mL}$; olefin, $500 \mu \mathrm{mol}$. Cr-containing silica: catalyst, $50 \mathrm{mg}$; photoirradiation time, $24 \mathrm{~h}(>400 \mathrm{~nm})$. TiO $\mathrm{O}_{2}$ : catalyst, $10 \mathrm{mg}$; photoirradiation time, $6 \mathrm{~h}(>320 \mathrm{~nm})$. TPT: catalyst, $50 \mu \mathrm{mol}$; photoirradiation time, $5 \mathrm{~h}(>400 \mathrm{~nm}) .{ }^{b}=[(\mathrm{PO}$ products $) /(\mathrm{PO}$ products $+(1 / 6) \mathrm{CO})]$. ${ }^{c}=[(\mathrm{PO}$ product yields)/(Cr (or TPT) amount on catalyst)]. 